\title{
Effect of Painting Therapy on Aggression in Educable Intellectually Disabled Students
}

\author{
Peyman Hashemian1, Lida Jarahi ${ }^{*}$ \\ ${ }^{1}$ Psychiatry and Behavioral Sciences Research Center, Ibn-e-Sina Hospital, Faculty of Medicine, Mashhad \\ University of Medical Sciences, Mashhad, Iran \\ ${ }^{2}$ Addiction Research Center, Faculty of Medicine, Mashhad University of Medical Sciences, Mashhad, Iran \\ Email:
}

Received 1 October 2014; revised 1 November 2014; accepted 18 November 2014

Copyright (C) 2014 by authors and Scientific Research Publishing Inc.

This work is licensed under the Creative Commons Attribution International License (CC BY). http://creativecommons.org/licenses/by/4.0/

(c) (7) Open Access

\begin{abstract}
Children with intellectual development disorder require to longer time for data processing. Delayed responses often exposed them to problematic condition like ignoring, stigma and physical or mental punishment. Intellectually disabled (ID) students also are in greater risk of psychological disorders such as anxiety and aggression based on problematic circumstances. This study was an experimental randomized controlled survey for assessment of painting therapy in reducing aggression in ID students. A total number of 20 educable ID children in elementary schools for student with special needs education in Bojnord City of Iran, were selected by using random sampling method in 2012. Participants were matched for age and educational level in intervention and control groups. According to Rotter and Goodenough test, after painting therapy, the mean scores of aggression in intervention group and control group were significantly different. The effect of painting therapy in male and female students was not statistically different. Painting therapy was effective method in reducing aggressive behaviors in ID students, as a complementary treatment in both male and female children. Painting therapy can be an effective method in similar behavioral problems in ID students.
\end{abstract}

\section{Keywords}

Painting Therapy, Aggression, Intellectual Disability, Children, Student

\section{Introduction}

Art therapy is application of art materials for empowering individual through the self-expression, self-identifi-

${ }^{*}$ Corresponding author. 
cation and personal conflicts resolution in the presence of a trained art therapist (Dalley, 2008; Rubin, 1999). Art therapy includes a wide range of approaches and therapeutic applications (Vick, 2003).

Art therapy is applicable in the form of visual arts approaches such as painting drawing, collage photography and sculpture and also in approach of music therapy, sociodrama, narrative therapy or by using of the literature (Kaldy, 2013; Pratt, 2004; Ross et al., 2008). As a psychological concept, art therapy was first introduced by Margaret Naumburg; she found that training painting art to children could facilitate free association and unconscious symbolic relation in objective and without censorship manner. Various areas of art therapy are used for treatment of different types of behavior problems, especially for reducing tension and aggression (Chen et al., 2014; Hocoy, 2005; Wells, Seabrook, Stolee, Borrie, \& Knoefel, 2003). Proper use of colors, is an important factor to reduce potential or actual aggression, for example it is suggested that pink may have calming effect if applied appropriately (Schauss, 1979).

Intellectual disability (mental retardation) characterized by limitation or impaired in intellectual and adaptive functioning, delays or lack of social skills. In intellectual disabled (ID) children aggression is a major problematic disorder due to poor attention, slowly data processing and delayed responses (Kryzhanovskaia, 1989; Sigelman et al., 1980). Learning disability of ID students can lead to dissatisfaction in their parents or teachers and sometimes cause to physical and psychological punishment, that is resulting child's emotional irritation, anxiety and aggression (Abolfotouh, El-Bourgy, Seif El Din, \& Mehanna, 2009). Some ID student showing disobey or they rebel in classroom to compensate their feelings about low self-empowerment, also common interest in ID children at home is watching TV, often they do not do suitable physical exercises, that all of these circumstances lead to these children use the aggression instead of proper physical activity (Simo-Pinatella et al., 2013). Children with aggressive behavior mostly face with poor interpersonal relationships and inappropriate social interaction and they may misinterpret social cues or use violence especially during periods of stress (Russell \& Russell, 1979).

Reducing aggression in students and prevention of damage caused by aggressive behaviors have great importance (Parciack, Winnik, \& Shmueli, 1975). Painting as a one of art therapy approaches allows ID children to express their emotions, which increases their self-esteem and consistency (Alavinezhad, Mousavi, \& Sohrabi, 2014; Hartz \& Thick, 2005). In dealing with children with abnormalities, the child may be afraid and worried about asking question, especially when the child inevitably uses his or her limited vocabulary to explain a sense or feeling. Providing intervention programs which be able to reduce aggressive behaviors can promote effectiveness of educational programs in ID students (Cusimano, Nastis, \& Zuccaro, 2013; Rose, 2013). The main objective of the present study was to investigate the therapeutic efficacy of paintings therapy on the level of aggression in educable ID students, and evaluation of the therapeutic effect of painting between the educable ID boys and girls.

\section{Methods}

This study was a randomized pretest-posttest control group research. The results of the pretest-posttest were analyzed with regard to the effectiveness of intervention (the effect of group) and also results compared in intervention and control groups. The study population was educable ID students, which was conducted in 2012 in the elementary schools for student with special needs education of Bojnord City in Iran. Twenty participants (10 participants per group) at the same age group and similar educational level were selected using random sampling method. The informed consent obtained from the parents of participants and oral informed consent obtained of the children based on their understanding.

Due to the presence of educable children and students younger than 15 years at these schools, having an IQ of 50 to 70 according to school recorded data, age between 8 to 15 years and have consent to participate in study were considered as the main inclusion criteria for entering the study. In addition, having visual, hearing and movement impairment, a specific speech and language disorder, epilepsy and medication were considered as exclusion criteria of this study.

The tools which were used in this study were Rutter Behavior Questions (form for teachers) and the Goodenough draw-a-person test. Because all evaluations were performed at the center of education, and participants were in a non-family situation, the teacher's form was selected as the primary assessment tools in this research. Rutter behavior questionnaire contains 30 questions and 5 subscales in which a total of 17 questions from four subscales including aggression and hyperactivity (7 questions), social conflict (6 questions), antisocial behaviors 
(7 questions) and attention deficits (5 questions) were used in the present study. The internal consistency coefficient for this test was 0.76 .

Goodenough draw-test (clinical scales) was used to measure the aggression in children. In this test, a paper and, seven colored pencils (purple, black, blue, green, yellow, brown and red), and the child is asked to draw a person. This test measures and describes the participants according to the four subscales. Implementation of this test is useful for the assessment of retarded people, especially those who have difficulty in understanding and producing language. In this study, the aggression is defined as the score that participants earn in the Rutter (teacher's form) and Goodenough clinical test.

Selected students were randomly allocated to intervention group (painting therapy) and the control group. Pretest exam was taken from all participants in the same condition. In intervention group painting therapy sessions were conducted for 12 sessions that each session was take 75 minutes, twice a week, those were carried out for 2 months. Student in control group received routine education and activity of their programs in school. Posttest exam was carried out after these two months in student of both groups. Data were analyzed by SPSS11.5 software for windows, by T-test and paired T-Test and in order to compare the experimental and control groups, ANCOVA was used.

\section{Results}

The mean age of participants was $9.1 \pm 0.9$ and $9.4 \pm 0.9$ in the intervention and the control group, respectively. The mean age of the boys and girls in the intervention group was $9.1 \pm 0.8$ and $9.1 \pm 1.1$, whereas in the control group the mean age of boys and girls was $9.8 \pm 1.1$ and $9.1 \pm 0.8$, respectively.

In the intervention group, $40 \%$ of the girls and $50 \%$ of the boys were in the first grade, while $60 \%$ of the girls and $50 \%$ of the boys were educated in second grade. In the control group $50 \%$ of the girls and $40 \%$ of the boys were in the first grade, whereas $50 \%$ of the girls and $60 \%$ of the boys were in the second grade.

According to Rotter test, the mean of aggression score in the intervention group was $7.7 \pm 1.6$ in pretest and $5.8 \pm 1.3$ in posttest. In control group, the mean of aggression score in the pretest and posttest was $7.7 \pm 1.6$ and $7.9 \pm 1.4$, respectively. The mean of aggression score in the intervention group, according to the Goodenough test was $13.2 \pm 2.2$ and $9.7 \pm 1.8$ in the pretest and posttest, respectively; while in the control group it was $13.2 \pm$ 2.5 in pretest and $13 \pm 2.5$ in posttest.

In the analysis of data using ANCOVA in the Rotter test, as shown in Table 1 according to the $\mathrm{F}_{(1,9)}=$ 179.102 and $P=0.005$, the effectiveness of painting therapy on reducing aggression was significant. And according to the $\mathrm{F}_{(1,9)}=1.706$ and $P=0.2$, there is no significant difference between experimental and control groups in terms of therapeutic effect of painting training (Table 1).

In Goodenough drawing test, according to the $\mathrm{F}_{(1,9)}=167.452$ and $P>0.0001$, the effect of painting therapy on reducing aggression was significant. Also according to $\mathrm{F}_{(1,9)}=7.182$ and $P=0.011$, there was significant difference between experimental and control groups in terms of therapeutic effect of painting therapy (Table 2).

In Rotter test therapeutic effects of painting therapy on aggression was significant, also there was no significant difference in the effectiveness of art therapy between male and female students $(P=0.7)$. In Goodenough clinical test the therapeutic effects of painting therapy on the level of aggression was significant, moreover there was significant difference in the effectiveness of painting therapy between boys and girls $(P=0.02)$ (Table 1 and Table 2).

The results of this study showed that there was no difference in the effectiveness of painting therapy on the level of ID students' aggression between boys and girls. This indicates a similar effect of painting therapy on both sexes $(P=0.31)$.

Table 1. Co-variance analysis of Rotter Questionnaire scores.

\begin{tabular}{cccccc}
\hline & Variable & Df & Mean square & F & $P$-value \\
\hline Intervention effect & Aggression & 1 & 0.343 & 179.102 & 0.001 \\
Intervention*group effect (interaction) & Aggression & 1 & 0.561 & 1.706 & 0.2 \\
Intervention*sex effect (interaction) & Aggression & 1 & 0.031 & 0.145 & 0.7 \\
\hline
\end{tabular}


Table 2. Co-variance analysis of Goodenough Questionnaire scores.

\begin{tabular}{cccccc}
\hline & Variable & Df & Mean square & F & $P$ \\
\hline Intervention effect & Aggression & 1 & 141.716 & 167.452 & $<0.001$ \\
Intervention*group effect (interaction) & Aggression & 1 & 6.07 & 7.182 & 0.01 \\
Intervention*sex effect (interaction) & Aggression & 1 & 4.02 & 6.102 & 0.02 \\
\hline
\end{tabular}

\section{Discussion}

The results of this study indicated that posttest aggression scores of the ID students in the intervention group were significantly different from the control group. These findings suggested that painting therapy was effective in reducing aggression in educable ID children.

Unique features of ID children appear in several ways including behavioral, emotional and academic patterns. These children use non-adaptive skills, but it seems that painting may help them to adjust to their surroundings, and to change their inappropriate behavioral patterns, prevention of damage caused by aggressive behaviors, especially if easily accessible treatment modalities such as painting therapy have great importance (Parciack et al., 1975). Painting is useful for improving cognition and in treatment of problems in non-adapted ID children (Alavinezhad et al., 2014; Hartz \& Thick, 2005). Consistent with these findings, Nouri and colleagues showed that painting therapy effectively reduce the level of violence and aggression in intellectually disabled children with aggressive behavior (Behpazhouh \& Nouri, 2003).

In a study by Kashani et al, the therapeutic effect of painting in reducing verbal and nonverbal aggression of ID female students at elementary school towards themselves or others and overall aggression was reported (Nezadi Kashani et al., 2011). The results of a study conducted by Karami and colleagues indicated that painting therapy led to a significant reduction in aggression in a group of female students who have been diagnosed with dyslexia (Karami, Alikhani, Zakiei, \& Khodadi, 2012). Also, the results of a study by Attari have demonstrated the reduction of anxiety in children who were treated with painting therapy (Attari, Shafi, \& Salimi, 2012).

In this regard and consistent with the present study, in some researches, the effectiveness of art therapies including music, dance or painting therapy in reducing aggression and anger has been emphasized, especially for people with vulnerable mental health (Argyle \& Bolton, 2005; Nissimov-Nahum, 2008; Pratt, 2004). Also in a study by Nasirzadeh and Roshan, storytelling reduced the signs of aggression in children and the reduction of the three-month follow-up remained stable (Nasirzadeh \& Roshan, 2010). Gholamzade and his colleagues showed that art therapy based on painting therapy significantly decrease the symptoms of oppositional defiant disorder (odd) in elementarily school Boys (Khadar, Babapour, \& Sabourimoghaddam, 2013).

\section{Conclusion}

Painting therapy as a complementary treatment method is effective in reducing aggression in ID students. By applying this method of art therapy indirect communication with children is possible and it can be used for similar behavior problems.

\section{Acknowledgements}

Researchers would like to acknowledge the staff of elementary schools for student with special needs education of Bojnord for their kind cooperation in this study.

\section{Competing Interests}

The authors declared that they have not competing interests.

\section{Authors' Contributions}

PH worked on the conceptualization, design, supervision of the data collection, preparation of manuscript draft. LJ helped in the interpretation, preparation of manuscript, revising, and editing. All authors have read and approved the final manuscript. 


\section{References}

Abolfotouh, M. A., El-Bourgy, M. D., Seif El Din, A. G., \& Mehanna, A. A. (2009). Corporal Punishment: Mother’s Disciplinary Behavior and Child’s Psychological Profile in Alexandria, Egypt. Journal of Forensic Nursing, 5, 5-17. http://dx.doi.org/10.1111/j.1939-3938.2009.01025.x

Alavinezhad, R., Mousavi, M., \& Sohrabi, N. (2014). Effects of Art Therapy on Anger and Self-Esteem in Aggressive Children. Procedia-Social and Behavioral Sciences, 113, 111-117. http://dx.doi.org/10.1016/j.sbspro.2014.01.016

Argyle, E., \& Bolton, G. (2005). Art in the Community for Potentially Vulnerable Mental Health Groups. Health Education, 105, 340-354. http://dx.doi.org/10.1108/09654280510617178

Attari, B., Shafi, A. A., \& Salimi, H. (2012). The Effectiveness of Teaching Painting on Decreasing the Amount of Anxiety in Elementary School Boys. Counseling Culture, 2, 47-64.

Behpazhouh, A., \& Nouri, F. (2003). The Effect of Painting Therapy on the Reduction of Aggressive Behavior in Mentally Retarded Children. Journal of Psychology and Education, 32, 155-170.

Chen, R. C., Liu, C. L., Lin, M. H., Peng, L. N., Chen, L. Y., Liu, L. K., \& Chen, L. K. (2014). Non-Pharmacological Treatment Reducing Not Only Behavioral Symptoms, but Also Psychotic Symptoms of Older Adults with Dementia: A Prospective Cohort Study in Taiwan. Geriatrics Gerontology International, 14, 440-446. http://dx.doi.org/10.1111/ggi.12126

Cusimano, M. D., Nastis, S., \& Zuccaro, L. (2013). Effectiveness of Interventions to Reduce Aggression and Injuries among Ice Hockey Players: A Systematic Review. CMAJ, 185, E57-E69. http://dx.doi.org/10.1503/cmaj.112017

Dalley, T. (2008). Art as Therapy: An Introduction to the Use of Art as a Therapeutic Technique. London: Routledge.

Hartz, L., \& Thick, L. (2005). Art Therapy Strategies to Raise Self-Esteem in Female Juvenile Offenders: A Comparison of Art Psychotherapy and Art as Therapy Approaches. Art Therapy, 22, 70-80.

http://dx.doi.org/10.1080/07421656.2005.10129440

Hocoy, D. (2005). Art Therapy and Social Action: A Transpersonal Framework. Art Therapy, 22, 7-16. http://dx.doi.org/10.1080/07421656.2005.10129466

Kaldy, J. (2013). Alternative Therapies for a New Era of Health Care. Consultant Pharmacist, 28, 84-90. http://dx.doi.org/10.4140/TCP.n.2013.84

Karami, J., Alikhani, M., Zakiei, A., \& Khodadi, K. (2012). The Effectiveness of Art Therapy (Painting) in Reducing the Aggressive Behavior of Students with Dyslexia. Journal of Learning Disabilities, 1, 105-117.

Khadar, M. G., Babapour, J., \& Sabourimoghaddam, H. (2013). The Effect of Art Therapy Based on Painting Therapy in Reducing Symptoms of Oppositional Defiant Disorder (ODD) in Elementary School Boys. Procedia-Social and Behavioral Sciences, 84, 1872-1878. http://dx.doi.org/10.1016/j.sbspro.2013.07.051

Kryzhanovskaia, I. L. (1989). Comparative Age-Related Characteristics of Psychopathy-Like Syndrome in Mentally Retarded Children. Zhurnal Nevropatologii i Psikhiatrii Imeni S. S. Korsakova, 89, 32-35.

Nasirzadeh, R., \& Roshan, R. (2010). The Effect of Storytelling on Aggression in Six to Eight-Year Old Boys. Iranian Journal of Psychiatry and Clinical Psychology, 16, 118-126.

Nezadi Kashani, G., Mirzamani, S. M., Davarmanesh, A., Salehi, M., Massah Choolaby, O., Hashemi, M., \& Gholami, A. (2011). The Effect of Painting in Reduction of Aggression in Educable Mentally Retarded Female Students in Primary School. Journal of Rehabilitation, 11, 80-87.

Nissimov-Nahum, E. (2008). A Model for Art Therapy in Educational Settings with Children Who Behave Aggressively. The Arts in Psychotherapy, 35, 341-348. http://dx.doi.org/10.1016/j.aip.2008.07.003

Parciack, R., Winnik, H. Z., \& Shmueli, M. (1975). Aggression in Painting-Painting as a Means of Release of Aggression. Mental Health and Society, 2, 225-237.

Pratt, R. R. (2004). Art, Dance, and Music Therapy. Physical Medicine and Rehabilitation Clinics of North America, 15, 827-841. http://dx.doi.org/10.1016/j.pmr.2004.03.004

Rose, J. (2013). A Preliminary Investigation into the Influence of Therapist Experience on the Outcome of Individual Anger Interventions for People with Intellectual Disabilities. Behavioural and Cognitive Psychotherapy, 41, 470-478. http://dx.doi.org/10.1017/S1352465812000823

Ross, S., Cidambi, I., Dermatis, H., Weinstein, J., Ziedonis, D., Roth, S., \& Galanter, M. (2008). Music Therapy: A Novel Motivational Approach for Dually Diagnosed Patients. Journal of Addictive Diseases, 27, 41-53. http://dx.doi.org/10.1300/J069v27n01_05

Rubin, J. A. (1999). Art Therapy: An Introduction. Hove: Psychology Press.

Russell, C., \& Russell, W. M. (1979). The Natural History of Violence. Journal of Medical Ethics, 5, 108-116. http://dx.doi.org/10.1136/jme.5.3.108 
Schauss, A. G. (1979). Tranquilizing Effect of Color Reduces Aggressive Behavior and Potential Violence. Journal of Orthomolecular Psychiatry, 8, 218-221.

Sigelman, C. K., Schoenrock, C. J., Spanhel, C. L., Hromas, S. G., Winer, J. L., Budd, E. C., \& Martin, P. W. (1980). Surveying Mentally Retarded Persons: Responsiveness and Response Validity in Three Samples. American Journal of Mental Deficiency, 84, 479-486.

Simo-Pinatella, D., Alomar-Kurz, E., Font-Roura, J., Gine, C., Matson, J. L., \& Cifre, I. (2013). Questions about Behavioral Function (QABF): Adaptation and Validation of the Spanish Version. Research in Developmental Disabilities, 34, 12481255. http://dx.doi.org/10.1016/j.ridd.2013.01.015

Vick, R. M. (2003). A Brief History of Art Therapy. In Handbook of Art Therapy (pp. 5-16).

Wells, J. L., Seabrook, J. A., Stolee, P., Borrie, M. J., \& Knoefel, F. (2003). State of the Art in Geriatric Rehabilitation. Part I: Review of Frailty and Comprehensive Geriatric Assessment. Archives of Physical Medicine and Rehabilitation, 84, 890897. http://dx.doi.org/10.1016/S0003-9993(02)04929-8 
Scientific Research Publishing (SCIRP) is one of the largest Open Access journal publishers. It is currently publishing more than 200 open access, online, peer-reviewed journals covering a wide range of academic disciplines. SCIRP serves the worldwide academic communities and contributes to the progress and application of science with its publication.

Other selected journals from SCIRP are listed as below. Submit your manuscript to us via either submit@scirp.org or Online Submission Portal.

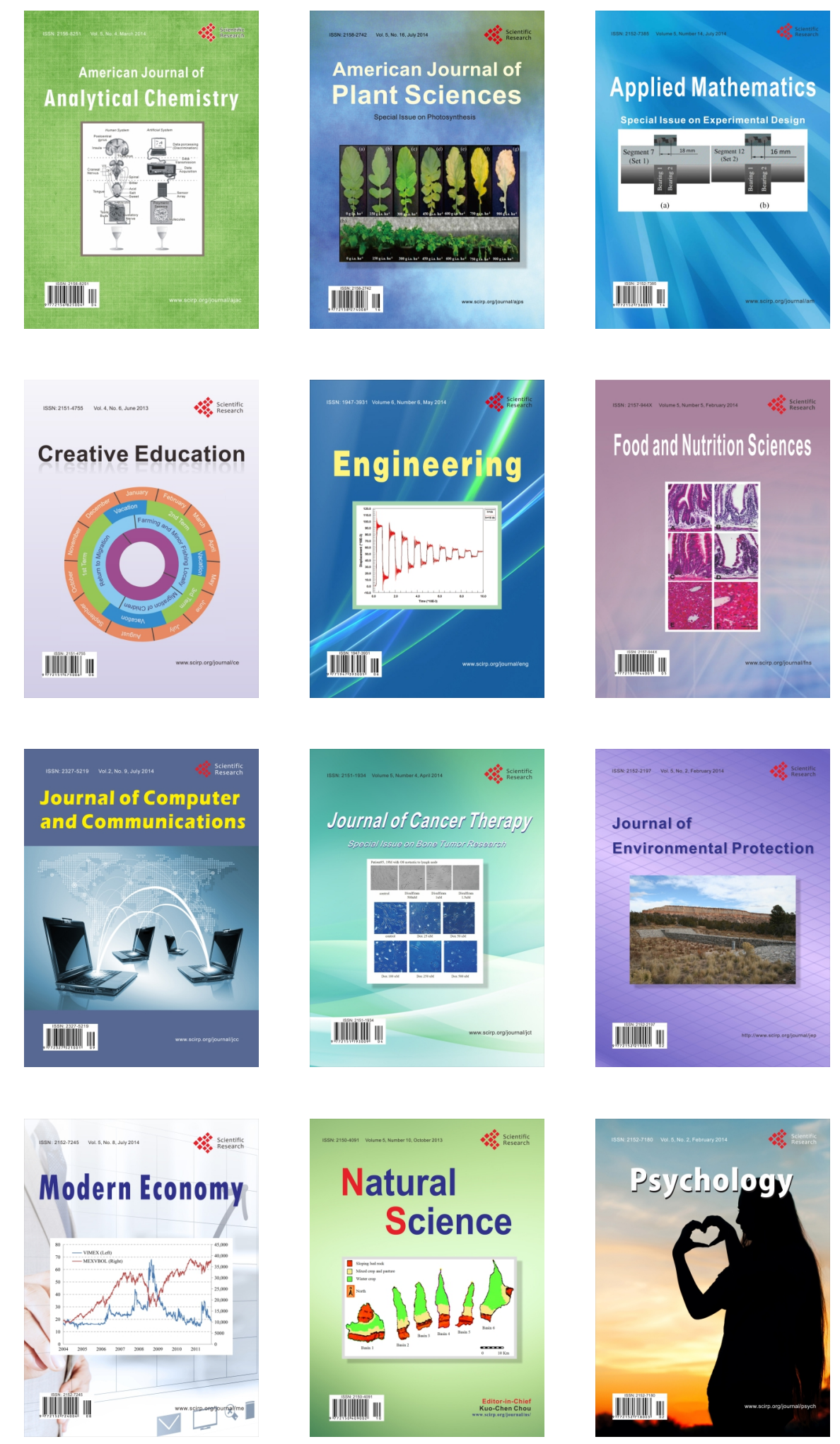